\title{
Influence of Strongly Dispersive Networks in a Microwave Interferometer under Non- Stationary Conditions
}

\section{Guldbrandsen, Tom; Nielsen, Lars Drud}

Published in:

Microwave Conference, 1977. 7th European

Link to article, DOI:

10.1109/EUMA.1977.332485

Publication date:

1977

Document Version

Publisher's PDF, also known as Version of record

Link back to DTU Orbit

Citation (APA):

Guldbrandsen, T., \& Nielsen, L. D. (1977). Influence of Strongly Dispersive Networks in a Microwave

Interferometer under Non-Stationary Conditions. In Microwave Conference, 1977. 7th European (pp. 561-565).

IEEE. https://doi.org/10.1109/EUMA.1977.332485

\section{General rights}

Copyright and moral rights for the publications made accessible in the public portal are retained by the authors and/or other copyright owners and it is a condition of accessing publications that users recognise and abide by the legal requirements associated with these rights.

- Users may download and print one copy of any publication from the public portal for the purpose of private study or research.

- You may not further distribute the material or use it for any profit-making activity or commercial gain

- You may freely distribute the URL identifying the publication in the public portal 
INFLUENCE OF STRONGLY DISPERSIVE NETWORKS IN A MICROWAVE INTERFEROMETER UNDER NON-STATIONARY CONDITIONS

Tom Guldbrandsen and Lars Drud Nielsen

A mathematical description is given of the errors that arise when dispersive transfer functions are measured under non-stationary conditions. The derived formula are checked by experiments with a tunable transmission cavity mounted in one arm of an $\mathrm{x}$-band interferometer. Power is given by a magnetron with a pulse width of $200 \mathrm{~ns}$, and the errors are consistently described in terms of the unintentional weak coherent modulation (AM and FM) of the input signal.

\section{INTRODUCTION}

This paper describes the errors that arise in measurements of fixed frequency parameters (viz. transmission or reflection) of dispersive components when the input signal is unintentionally modulated in amplitude and/or frequency. The output signal from the dispersive component is then not determined solely by the input instantaneous frequency and amplitude, but depends on the behaviour of the input signal during a preceding time interval, roughly equal to the delay of the component.

\section{DESCRIPTION OF A WEAKLY MODULATED SIGNAL}

A weakly modulated signal may be approximated around an arbitrary time origin $t$, either in terms of instantaneous phase, frequency, and frequency derivative (all complex quantities), or as a sum of a carrier wave of complex frequency and two symmetric side bands:

$$
\begin{aligned}
v(t+\Delta t) & \simeq \operatorname{Re}\left\{e^{j\left(\phi_{i}+\omega_{i} \Delta t+\frac{1}{2} \dot{\omega}_{i} \Delta t^{2}\right)}\right\} \\
& \simeq \operatorname{Re}\left\{e^{j \phi_{i}}\left[(I+2 a) e^{j \omega_{i} \Delta t}-a \cdot e^{j\left(\omega_{i}+\Omega\right) \Delta t}-a \cdot e^{j\left(\omega_{i}-\Omega\right) \Delta t}\right]\right\}
\end{aligned}
$$

The two expressions are consistent to second order in $\Delta t$, provided:

$$
a \Omega^{2} \equiv \frac{1}{2} j \dot{\omega}_{i}
$$

All the expansion coefficients $\phi_{i}, \omega_{i}, \dot{\omega}_{i}, a$, and $\Omega$ will depend on time $t$. $a$ and $\Omega$ will at the end of calculations always appear as combined in (2).

\section{DESCRIPTION OF TRANSFER FUNCTIONS}

The frequency dependence of a transfer function $H(j \omega)$ is conveniently described by an expansion around a fixed frequency $\omega_{0}$ in the range of interest:

$$
\mathrm{H}\left[\mathrm{j}\left(\omega_{0}+\Delta \omega\right)\right]=\mathrm{H}_{0} \cdot\left[1-j \Delta \omega \tau-\frac{1}{2} \Delta \omega^{2}\left(\tau^{2}+\tau^{\prime}\right)\right]
$$

Physics Laboratory III, Technical University of Denmark, DK-2800 Lyngby, Denmark. 
where:

$$
\mathrm{H}_{0} \equiv \mathrm{H}\left(j \omega_{0}\right), \tau \equiv-\left.\frac{\mathrm{d} \ell \mathrm{ln}}{\mathrm{d}(j \omega)}\right|_{\omega_{0}},\left.\tau^{\prime} \equiv \frac{\mathrm{d}^{2} \ell \mathrm{lnH}}{\mathrm{d}(j \omega)}\right|_{\omega_{0}}=-\left.\frac{\mathrm{d} \tau}{d(j \omega)}\right|_{\omega_{0}}
$$

$\tau$ is readily interpreted as the (complex) group delay of the circuit. For a transmission line of length $\ell$ and group velocity $v_{g}$ one obtains $\tau=\ell v_{g}$ and $\tau^{\prime} \simeq 0$.

For a transmission cavity with the transfer function:

$$
H(j \omega)=\frac{1}{1+2 j Q \frac{\omega-\omega_{\text {res }}}{\omega_{\text {res }}}}
$$

one obtains:

$$
\tau=\tau_{\text {res }}{ }^{\mathrm{H}} 0^{\prime} \quad \tau^{\prime}=\tau_{\text {res }}^{2}{ }^{\mathrm{H}} 0^{\prime}, \quad \text { where } \tau_{\text {res }} \equiv \frac{2 Q}{\omega_{\text {res }}}
$$

The side band terms $(\Delta \omega= \pm \Omega)$ in (lb) are now seen to be a potential source of error in an experimental determination of dispersive transfer functions (3). We have been concerned with the case of a coherently modulated repetitive sinewave-burst, so that the effect gives rise to a systematic error on the measurements of transfer functions.

\section{METHOD OF INVESTIGATIONS}

Fig. I shows the experimental set up, which is a high precision complex microwave transmission bridge (inteferometer) fed by a $9.375 \mathrm{GHz}$ magnetron with a pulse width of $200 \mathrm{~ns}$. The unbalance signal is SSB-SC modulated

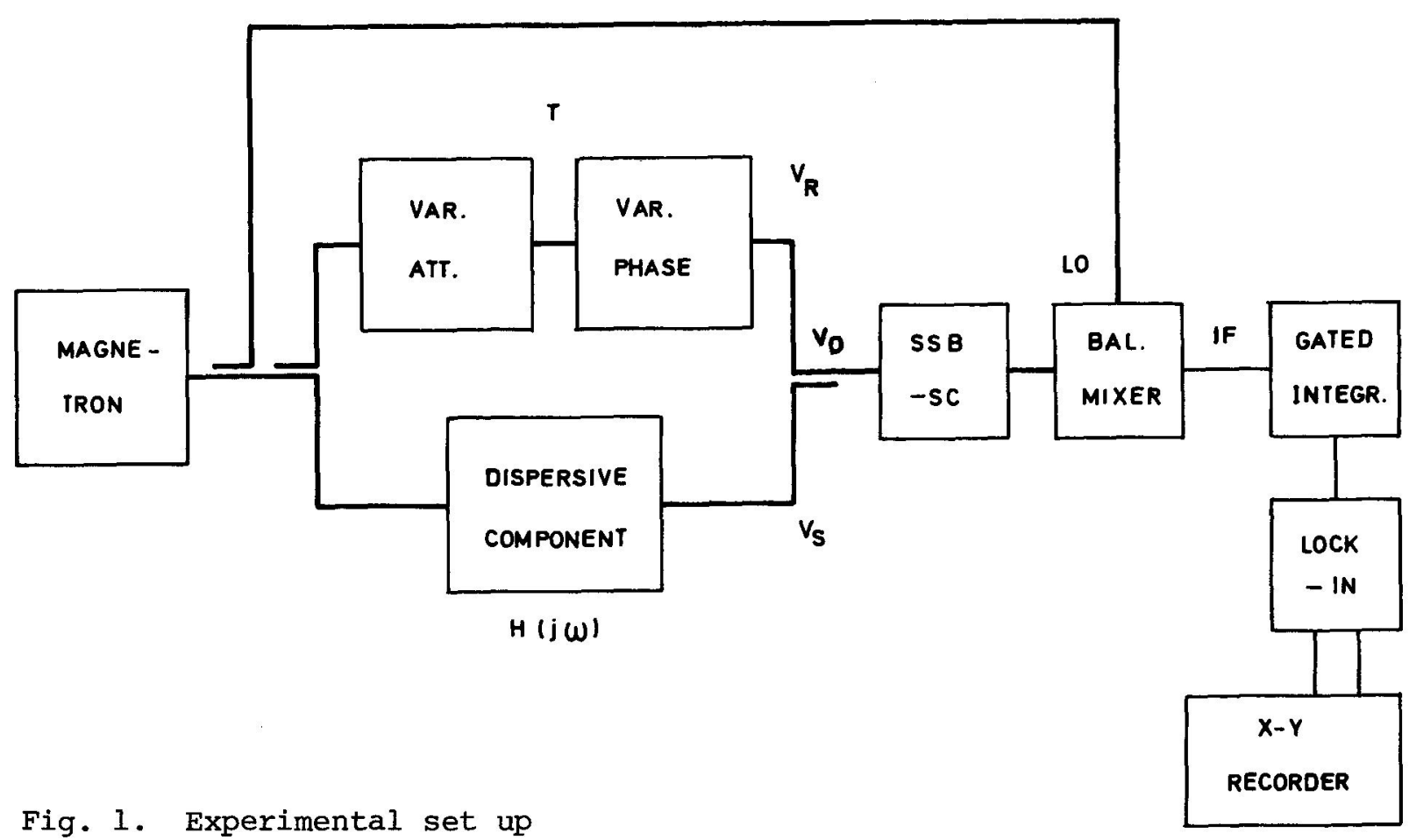


(Single Side Band-Suppressed Carrier) by means of a motordriven rotary vane phase shifter and mixed with the input signal. The IF signal is sampled by a gated integrator at some adjustable time $t$ after the beginning of the pulse and is then processed by a 2-phase lock-in amplifier. The outputs are fed to an $\mathrm{X}-\mathrm{Y}$ recorder that gives a direct display of the complex unbalance signal $\mathrm{V}_{0}=\mathrm{V}_{R}-\mathrm{V}_{S^{\prime}}$, where $\mathrm{V}_{\mathrm{R}}$ and $\mathrm{V}_{S}$ are the complex signals through reference and sample branches, respectively.

All complex representatives are referred to the instantaneous complex frequency $\omega_{i}$ of the input signal. $v_{R}$ is obtained from the input signal (1) by multiplication with a known and non-dispersive transmission coefficient $T$, whereas $v_{S}$ is found by combining (lb) $(\Delta t=0)$ and (3) with $\omega_{0}=\omega_{i} \quad\left(H_{0}=H_{i}\right)$ and $\Delta \omega= \pm \Omega$. Hence:

$$
\begin{aligned}
v_{O}(t) & =v_{R}(t)-v_{S}(t) \\
& =T e^{j \phi_{i}}-H_{i} e^{j \phi_{i}}\left[(1+2 a)-a\left(1-j \Omega \tau-\frac{1}{2} \Omega^{2}\left(\tau^{2}+\tau^{\prime}\right)\right)-a\left(1+j \Omega \tau-\frac{1}{2} \Omega^{2}\left(\tau^{2}+\tau^{\prime}\right)\right)\right] \\
& =e^{j \phi_{i}}\left[\left(T-H_{i}\right)-\frac{1}{2} j \dot{\omega}_{i}\left(\tau^{2}+\tau^{\prime}\right) H_{i}\right]
\end{aligned}
$$

where (2) has been used at the end.

Reading of the transmission coefficient in the balance situation $\left(v_{0}=0\right)$ thus yields:

$$
T_{b a l}=H\left(j \omega_{i}\right)\left[1+\frac{1}{2} j \dot{\omega}_{i}\left(\tau^{2}+\tau^{\prime}\right)\right]
$$

So, $\mathrm{T}_{\mathrm{bal}}$ as a measure of the investigated transfer function will contain a relative error proportional to the time derivative $\dot{\omega}_{i}$ of the instantaneous complex frequency and dependent on the circuit parameters $\tau$ and $\tau$ '. As seen from (6), the error is largest for high-Q circuits, especially in the vicinity of resonance. By proper choice of sampling time it is possible to minimize $\dot{\omega}_{i}$, or at least one of its components, in order suit the requirements of specific experiments.

The experimental evidence for the validity of (7) and (8) has been searched for through a careful analysis of the unbalance signal versus sampling time for a tunable cavity (5). For each value of $\omega_{\text {res }}$ the bridge was balanced at a sampling time $t_{0}=110 \mathrm{~ns}$ measured from the beginning of the magnetron pulse, and $v_{O}$ was recorded versus sampling time in the range $50 \mathrm{~ns}<t<170 \mathrm{~ns}$. Dividing $\mathrm{Eq}$. (7) by $\mathrm{V}_{\mathrm{R}}=\mathrm{Te} \mathrm{e}_{i}$, the following equation is obtained by means of (3) and under the assumption of weak modulation:

$$
\left.\frac{v_{O}}{v_{R}}\right|_{t_{0}} ^{t}=j\left[\left.\omega_{i}\right|_{t_{0}} ^{t} \cdot \tau-\left.\frac{1}{2} \dot{\omega}_{i}\right|_{t_{0}} ^{t} \cdot\left(\tau^{2}+\tau^{\prime}\right)\right]
$$

The first term arises directly from the frequency dependence of the transfer function, whereas the last term is a consequence of the memory effect of the circuit. In order to separate the two contributions, Eq. (9) is considered for a fixed value of $t$, but for different tunings of the cavity $\left(\omega_{\text {res }}\right)$. Introduction of $(6)$ and $\mathrm{H}_{0} \simeq \mathrm{T}_{\overline{\mathrm{z}}} \mathrm{z}^{-1}$ yields :

$$
\left.w_{t}(z) \equiv \frac{1}{T^{2}} \frac{v_{O}}{v_{R}}\right|_{t_{0}} ^{t}=j\left[\omega_{i} \tau_{r e s} z-\dot{\omega}_{i} \tau_{r e s}^{2}\right]_{t_{0}}^{t}
$$


The linear complex function $w_{t}(z)$ is for each value of $t$ completely determined by measurements along the line $z=l+j y$, and with a knowledge of $\tau_{\text {res }}=$ $2 Q / \omega_{\text {res }}$ we can extract the two quantities:

$$
\begin{gathered}
\left.w_{i}\right|_{t_{0}} ^{t}=\frac{-j}{\tau_{\text {res }}} \frac{d w_{t}}{d z} \\
\left.\dot{\omega}_{i}\right|_{t_{0}} ^{t}=\frac{j}{\tau_{\text {res }}^{2}} w_{t}(0)=\frac{j}{\tau_{\text {res }}^{2}}\left[w_{t}(1)-\frac{d w_{t}}{d z}\right]
\end{gathered}
$$

and check the consistency between $\omega_{i}(t)$ and $\dot{\omega}_{i}(t)$.

\section{RESULTS}

The cavity used in the investigations was not specially designed for the purpose of maximizing non-stationarity effects and did therefore not have a very high $Q$. Comparison of results for the cavity and for a known transmission line delay, under the assumption that $\mathrm{Eq}$. (9) was dominated by the first term, yielded $\tau_{\text {res }}=6 \mathrm{~ns}$. This corresponds to $\mathrm{Q}=177$, which is in good agreement with estimates based on the geometry of the cavity and measurements of the load from the two ports.

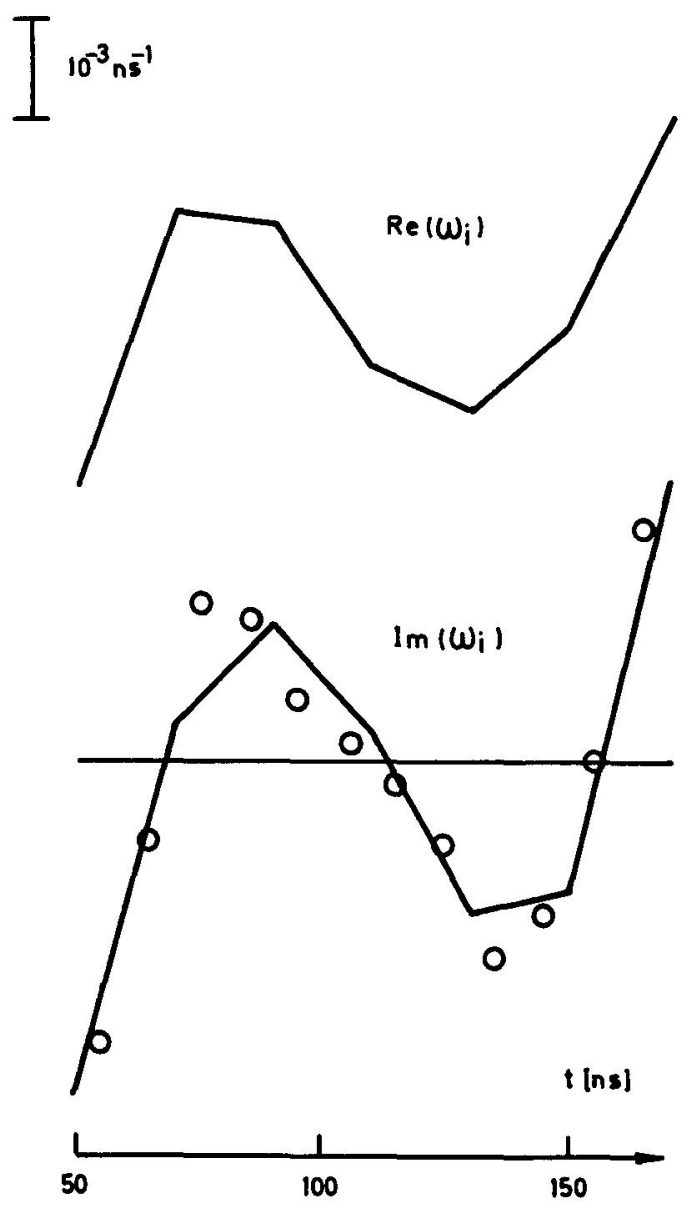

Fig. 2. Curves of instantaneous complex frequency, derived from (11). Circles indicate results for $\operatorname{Im}\left(\omega_{i}\right)$ obtained from pulse envelope and define the zero level for $\operatorname{Im}\left(\omega_{i}\right)$.

$$
\perp^{10^{-4} \mathrm{~ns}^{-2}}
$$
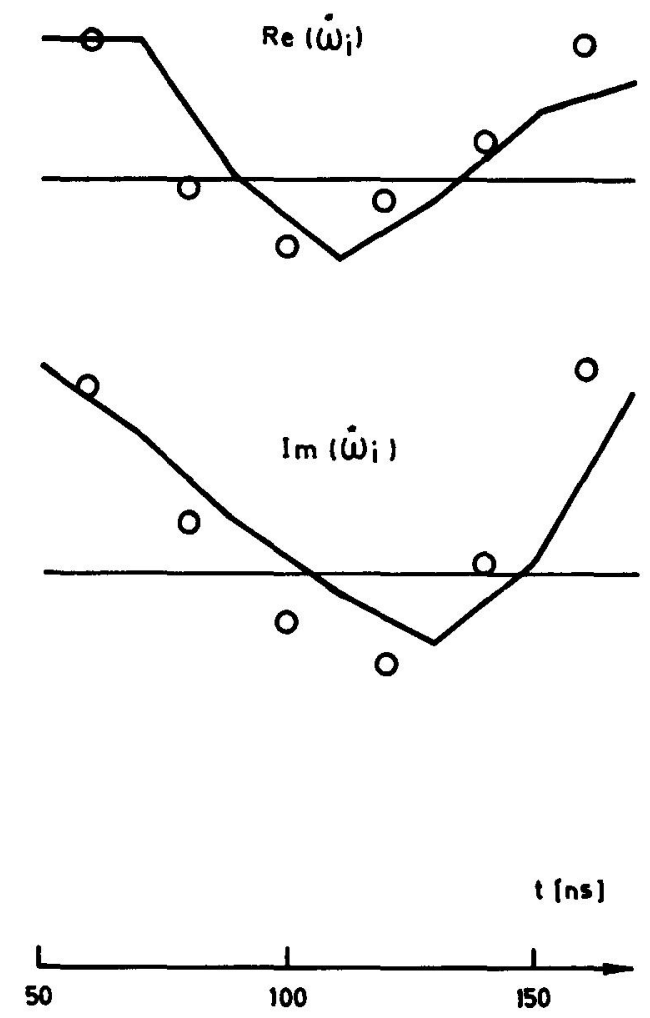

Fig. 3. Curves of instantaneous complex frequency derivative, derived from (12). Circles indicate results obtained by differentiation from Fig. 2 and define the zero levels. 
Figs. 2 and 3 show results obtained by the analysis described in the preceding section (with $\tau_{\text {res }}=6 \mathrm{~ns}$ ) for $\omega_{i}$ and $\dot{\omega}_{i}$, respectively. Both complex quantities are only determined with reference to their values at $t_{0}=110 \mathrm{~ns}$. $\operatorname{Im}\left(\omega_{i}\right)$, which describes the amplitude modulation of the signal, is compared in Fig. 2 with the results obtained from a direct observation of the pulse envelope. The results for $\dot{\omega}_{i}$ in Fig. 3 are compared with a simple numerical differentiation of $\omega_{i}$, and the nice agreement provides the evidence that our description of the non-stationarity phenomena is satisfactorily complete.

\section{CONCLUSION}

Measurements of transfer functions of dispersive networks under not strictly stationary conditions will generally give rise to errors proportional to the time derivative of the instantaneous complex frequency, and of substantial size in the case of high-Q circuits. The non-stationarity may have the form of either a noisy or a coherent modulation of narrow bandwidth. In cases of coherent modulation the errors will be predictable and might be taken into account, if necessary. 